\title{
Spectrofluorimetric determination of sertraline in dosage forms and human plasma through derivatization with 9-fluorenylmethyl chloroformate
}

\author{
Nahed M El-Enany", Amina Abdelal and Fathalla Belal
}

\begin{abstract}
Background: Sertraline is primarily used to treat major depression in adult outpatients as well as obsessivecompulsive, panic and social anxiety disorders in both adults and children. A survey of the literature reveals that most of the reported methods are either insufficiently sensitive or tedious and require highly sophisticated and dedicated instrumentation. The proposed method is considered to be specific for determination of SER in presence of its metabolite (deaminated form).

Results: A sensitive, simple and specific spectrofluorimetric method was developed for the determination of sertraline (SER) in pharmaceutical formulations and biological fluids. The method is based on its reaction with 9fluorenylmethyl chloroformate (FMOC-Cl) in borate buffer of pH 8.0 to yield a highly fluorescent derivative peaking at $315 \mathrm{~nm}$ after excitation at $265 \mathrm{~nm}$. The different experimental parameters affecting the development and stability of the reaction product were carefully studied and optimized. The fluorescence concentration plot was rectilinear over the range of $0.05-1.0 \mu \mathrm{g} \mathrm{mL}^{-1}$ with a lower detection limit of $5.34 \times 10^{-3} \mathrm{\mu g} \mathrm{mL}^{-1}$ and limit of quantitation of $0.016 \mu \mathrm{g} \mathrm{mL}$.

Conclusions: The proposed method was successfully applied to the analysis of commercial tablets and the results obtained were in good agreement with those obtained using the reference method. Furthermore, the method was applied for the determination of SER in spiked and real human plasma. The mean \% recovery $(n=3)$ was $94.33 \pm$ 1.53 and $92.00 \pm 2.65$, respectively. A proposal of the reaction pathway was postulated.
\end{abstract}

\section{Background}

Sertraline (SER); (1S)-cis-4-(3,4-dichlorophenyl)-1,2,3,4tetrahydro- $N$-methyl-1-naphthalenamine (Figure 1) is primarily used to treat major depression in adult outpatients as well as obsessive-compulsive, panic and social anxiety disorders in both adults and children. The efficacy of sertraline for depression is similar to that of older tricyclic antidepressants, but its side effects are much less pronounced [1].

Several methods have been reported for the determination of SER either per se or in pharmaceutical preparations and biological fluids. These methods include:

\footnotetext{
* Correspondence: nelenany1@yahoo.com

Department of Pharmaceutical Analytical Chemistry, Faculty of Pharmacy, University of Mansoura, 35516, Mansoura, Egypt
}

spectrophotometry [2-4], voltammetry [5], HPLC [6-11] gas chromatography $[12,13]$. A literature review up to 2008 has been described by Espinosa et al [14]. The review described the different analytical methodologies for the determination of SER chromatography [14] and liquid mass spectrometry $[15,16]$.

Most of these methods are either insufficiently sensitive [2-4] or tedious and require highly sophisticated and dedicated instrumentation [6-16]. This led us to study the reaction of sertraline with 9-fluorenylmethyl chloroformate (FMOC-Cl) in an attempt to develop a simple and sensitive spectrofluorimetric method for its determination in pharmaceutical preparations and biological fluids.

9-Fluorenylmethyl chloroformate is a useful derivatizing agent used for the determination of amino acids, 


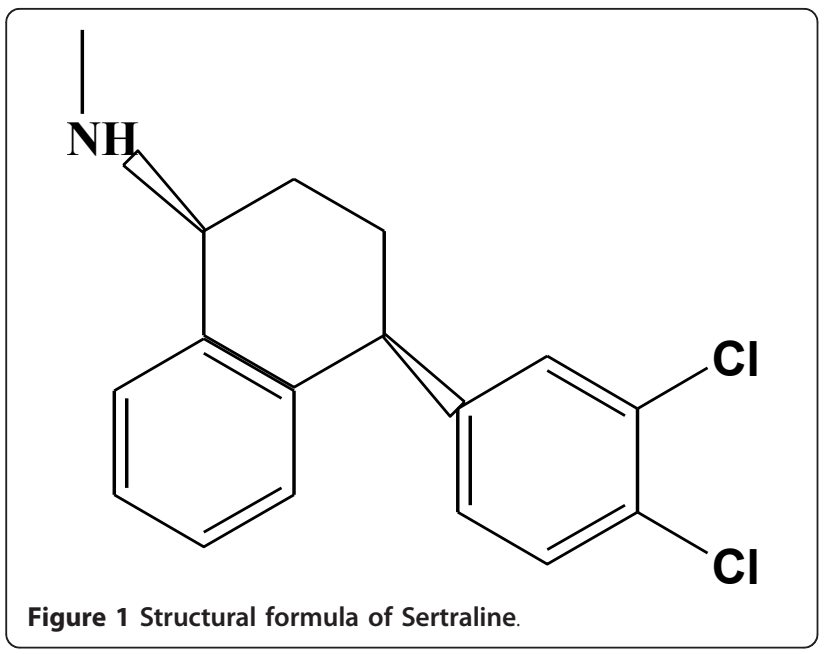

primary amines and secondary amines. Several pharmaceutical compounds have been determined through this approach [16-21].

To the best of our knowledge, up till now nothing has been reported concerning the spectrofluorimetric determination of sertraline. This encouraged us to develop a simple and sensitive method for its determination in tablets and human plasma. The results obtained were promising.

\section{Experimental}

\section{Instrumentation}

The fluorescence spectra and measurements were recorded using a Perkin-Elmer UK model LS 45 luminescence spectrometer, equipped with a 150 Watt Xenon arc lamp, grating excitation and emission monochromators for all measurements and a PerkinElmer recorder. Slit widths for both monochromators were set at $10 \mathrm{~nm}$. A $1 \mathrm{~cm}$ quartz cell was used. Derivative spectra were evaluated using Fluorescence Data Manager (FLDM) software. Sofware used is FL WINLAB, Version 4.00.02, copyright 2001, Perkin Elmer, Inc., UK.

\section{Reagents and materials}

All reagents and solvents used were of Analytical Reagent grade.

(a) Setraline pure sample was kindly provided by Pfizer (Sandwich, UK).

(b) Tablets containing sertraline $\mathrm{HCl}$ equivalent to 50 mg of sertraline base each (Lustral ${ }^{\mathbb{B}}$ tablets), batch \# 7201 were obtained from commercial sources in the local market.

(c) 9-fluorenylmethyl chloroformate (FMOC-Cl), was purchased from Sigma (St. Louis USA). A stock solution containing $20 \mathrm{mg} \%$ of FMOC-Cl was freshly prepared in acetonitril and was further diluted with the same solvent to obtain $0.01 \mathrm{mg} \%$ solution. (d) Borate buffer $0.2 \mathrm{M}$ solutions of $\mathrm{pH}$ 8.0. and $\mathrm{pH}$ 12.

(e) Acetonitrile, acetone and diethylether (Merck, Darmstadt, Germany).

(f) Human plasma samples were kindly provided by Mansoura University Hospital, Mansoura, Egypt and was kept frozen at $-2^{\circ} \mathrm{C}$ until assay after gentle thawing.

\section{Standard Solutions}

A stock solution was prepared by dissolving $20.0 \mathrm{mg}$ of SER in $100 \mathrm{~mL}$ of acetonitrile in a volumetric flask. This solution was further diluted with the same solvent as appropriate. The standard solutions were stable for seven days when kept in the refrigerator.

\section{General recommended procedures}

\section{Procedure for calibration graph}

Aliquots of SER standard solutions were transferred into a series of $10 \mathrm{~mL}$ volumetric flasks. Borate buffer, $\mathrm{pH}$ $8.0(2.5 \mathrm{~mL})$ was added, followed by FMOC-Cl $(0.01 \mathrm{mg}$ \%) $(2 \mathrm{~mL})$ and mixed well. Acetonitril $(3 \mathrm{~mL})$ were added. The reaction mixture was left at room temperature for $15 \mathrm{~min}$., and then completed to the mark with distilled water. The fluorescence intensity of the reaction product was measured at $315 \mathrm{~nm}$ after excitation at 265 $\mathrm{nm}$. A blank experiment was carried out simultaneously. The corrected fluorescence intensity was plotted $v s$ the final drug concentration $\left(\mu \mathrm{g} \mathrm{mL}{ }^{-1}\right)$ to get the calibration graph. Alternatively, the corresponding regression equation was derived.

\section{Assay procedure for Tablets}

Twenty tablets were weighed and pulverized well. A weighed quantity of the "powder, equivalent" to $20.0 \mathrm{mg}$ of SER was transferred into a small conical flask, and extracted with $3 \times 30 \mathrm{~mL}$ of actonitril. The extract was filtered into $100 \mathrm{~mL}$ volumetric flask. The conical flask was washed with few milliliters of acetonitril. The washings were passed into the same volumetric flask and made up the mark with the same solvent. Aliquots covering the working concentration range was transferred into $10 \mathrm{~mL}$ volumetric flasks. The procedure described under "General recommended procedures" "was then applied. The nominal content of the tablets was determined either from the calibration curve or by using the corresponding regression equation.

\section{Assay procedure for spiked human plasma}

A stock solution containing $20.0 \mu \mathrm{g} \mathrm{mL}^{-1}$ of SER was prepared in acetonitrile. Control samples of plasma were spiked with different quantities of SER. Acetone $(2 \mathrm{~mL})$ was added, then the mixture was vortexed and centrifuged at $3500 \mathrm{xg}$ for $10 \mathrm{~min} .3 \mathrm{~mL}$ of the clear supernatant was separated, and borate buffer, $\mathrm{pH} 12(1 \mathrm{~mL})$ was 
added. The solution was extracted with $3 \times 5 \mathrm{~mL}$ of diethylether for $2 \mathrm{~min}$, then centrifuged at $3500 \mathrm{xg}$ for 5 $\mathrm{min}$. The resulting supernatant was evaporated to dryness under nitrogen at ambient temperature. The residue was dissolved in $2 \mathrm{~mL}$ of acetonitrile. The general recommended procedures applied for pure sample were then performed. The nominal content of the drug was determined using the corresponding regression equation.

\section{Assay procedure for real human plasma samples}

As for the real human plasma, SER (50 mg/tablet) was orally administered to a fasting healthy volunteer (male, 40 years old). $5 \mathrm{~mL}$ of blood sample was withdrawn after four hours. Then, $4 \mathrm{~mL}$ of citrate solution was added, and centrifuged at $3500 \mathrm{rpm}$ for $15 \mathrm{~min}$. to obtain ca $3 \mathrm{~mL}$ of plasma. The methodology described under the "procedure for spiked human plasma" was then carried out. The nominal content of SER in plasma was determined according to previous report [22] using the following equation:

Recovery $_{\text {in vivo }}=$ Delivery $_{\text {in vivo }} \times$ Recovery $_{\text {in vitro }} /$ Delivery $_{\text {in vitro }}$

\section{Results and Discussion}

FMOC-Cl was chosen as a fluoregnic derivatizing agent for SER because of its superior properties, as compared to other reagents. It reacts under mild conditions with primary and secondary amines in alkaline medium and the resulting derivatives are stable.

It has been utilized for the determination of amino acids and primary amines [16]. Recently $\mathrm{FMOC}-\mathrm{Cl}$ was further used for the analysis of some pharmaceutical compounds containing primary or secondary amino groups viz; trimetazine [17] roxithromycin [18] clarithromycin [19] alendronate [20] and topiramate [21].

In the present study, SER was found to react with FMOC-Cl at $\mathrm{pH} 8.0$ forming a highly fluorescent derivative with $\lambda$ maximum of $315 \mathrm{~nm}$ after excitation at 265 nm (Figure 2).

\section{Study of Experimental Parameters}

The spectrofluorimetric properties of the reaction product as well as the different experimental parameters affecting its development and its stability were carefully studied and optimized. Such factors were changed individually while the others were kept constant. The factors included $\mathrm{pH}$, type of buffer, volume of buffer, concentration of the reagent, reaction time and volume of acetonitrile.

\section{i. Effect of $\mathrm{pH}$}

The influence of $\mathrm{pH}$ on the fluorescence intensity of the reaction product was evaluated. Maximum fluorescence

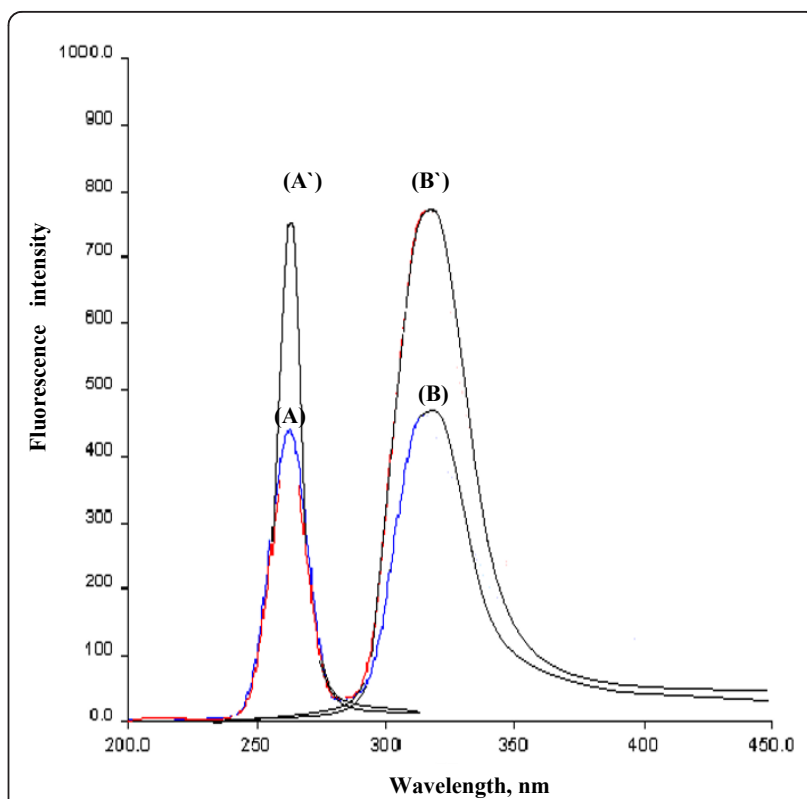

Figure 2 Fluorescence spectra of excitation and emission. (A) Excitation spectra of blank (B) Emission spectra of blank ( $A^{\prime}$ ) Excitation spectra of SER $\left(1 \mu \mathrm{g} \mathrm{mL}^{-1}\right)$ with FMOC-Cl at pH $8.0\left(\mathrm{~B}^{\prime}\right)$ Emission spectra of SER $\left(1 \mu \mathrm{g} \mathrm{mL}^{-1}\right)$ with FMOC-Cl at pH 8.0.

intensity was obtained at $\mathrm{pH} 7.8$ and remained constant up to 8.2 after which the fluorescence intensity of the reaction product began to decrease gradually until $\mathrm{pH}$ 13. Therefore, $\mathrm{pH}$ of 8.0 was chosen as the optimum $\mathrm{pH}$ (Figure 3). Other buffers having the same $\mathrm{pH}$ value such as phosphate and hexamine were tried and compared with $0.2 \mathrm{M}$ borate buffer. Borate buffer was found to be superior to phosphate and hexamine buffers having the same $\mathrm{pH}$ value since the net fluorescence intensity was highest in the case of borate buffer.

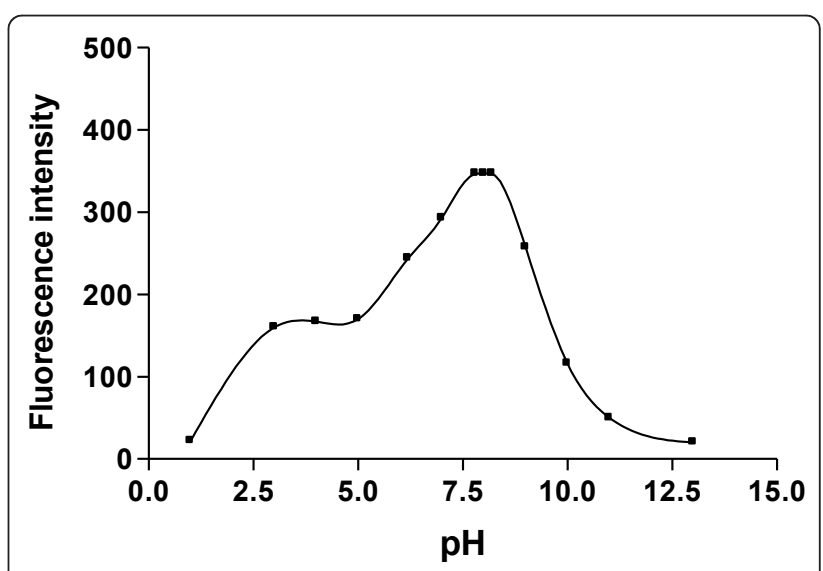

Figure 3 Effect of $\mathrm{pH}$ on the fluorescence intensity of SER (1 $\mu \mathrm{g} \mathrm{m}^{-1}$ ) with FMOC-Cl. 


\section{ii. Effect of volume of buffer}

It was found that increasing the volume of $0.2 \mathrm{M}$ borate buffer of $\mathrm{pH} 8.0$ up to $2 \mathrm{~mL}$ resulted in a gradual increase in the fluorescence intensity of the reaction product and after which it remained constant till $3 \mathrm{~mL}$, therefore $2.5 \mathrm{~mL}$ of the buffer was chosen as the optimal volume throughout the study.

\section{iii. Effect of concentration of $\mathrm{FMOC}-\mathrm{Cl}$}

The influence of the concentration of FMOC-Cl was studied using different volumes of $0.01 \mathrm{mg} \%$ of the reagent solution. It was found that the reaction of FMOC-Cl with SER started upon using $0.25 \mathrm{~mL}$ of the reagent in the presence of borate buffer $(\mathrm{pH} 8.0)$. Increasing the volume of the reagent produces a proportional increase in the fluorescence intensity of the reaction product up to $1.8 \mathrm{~mL}$ and remains constant up to $2.2 \mathrm{~mL}$. Therefore, $2 \mathrm{~mL}$ of $0.01 \mathrm{mg} \%$ of FMOC-Cl solution was chosen as the optimal volume of the reagent.

\section{iv. Effect of temperature}

Increasing the reaction temperature higher than the room temperature up to boiling for 20 minutes. resulted in a subsequent decrease in the fluorescence intensity of the reaction product.

\section{$v$. Effect of reaction time}

Different time intervals were tested to ascertain the time after which the solution attained its highest fluorescence intensity. It was found that after 10 minutes the reaction product reached the highest fluorescence intensity and remained stable up to $20 \mathrm{~min}$, after which very slight decrease in the fluorescence intensity of the reaction product was observed (Figure 4). Therefore, the reaction product was measured after $15 \mathrm{~min}$ at room temperature $\left(25^{\circ} \mathrm{C}\right)$.

\section{vi. Effect of volume of acetonitril}

It was found that, $3 \mathrm{~mL}$ of acetonitril was sufficient to produce maximum and constant fluorescence intensity of the reaction product. The reaction between FMOC$\mathrm{Cl}$ and SER takes place in an aqueous -organic phase system due to insolubility of FMOC-Cl and reaction product in water. It was necessary to perform the reaction with high content of acetonitril (final concentration, $60 \%)$

\section{Validation of the proposed method}

The validity of the method was tested regarding; linearity, specificity, accuracy, repeatability and precision according to ICH Q2B recommendations [23].

\section{Linearity}

By using the above procedure, linear regression equation was obtained. The regression plots showed that there was a linear dependence of the fluorescence intensity on the concentration of the drug over the ranges shown in Table 1linear to coefficient is superfluous as data is already in the table. A linear regression analysis of the data gave the following equation:

$$
\mathrm{F}=-0.66+346 \mathrm{C} \quad(\mathrm{r}=0.9999)
$$

where $\mathrm{F}$ is the fluorescence intensity, $\mathrm{C}$ is the concentration of the drug in $\mu \mathrm{g} / \mathrm{ml}$ and $\mathrm{r}$ is the correlation coefficient.

The limit of quantification (LOQ) was determined by establishing the lowest concentration that can be measured according to ICH Q2B [23]. The results are shown in Table 1. The limit of detection (LOD) was determined by establishing the minimum level at which

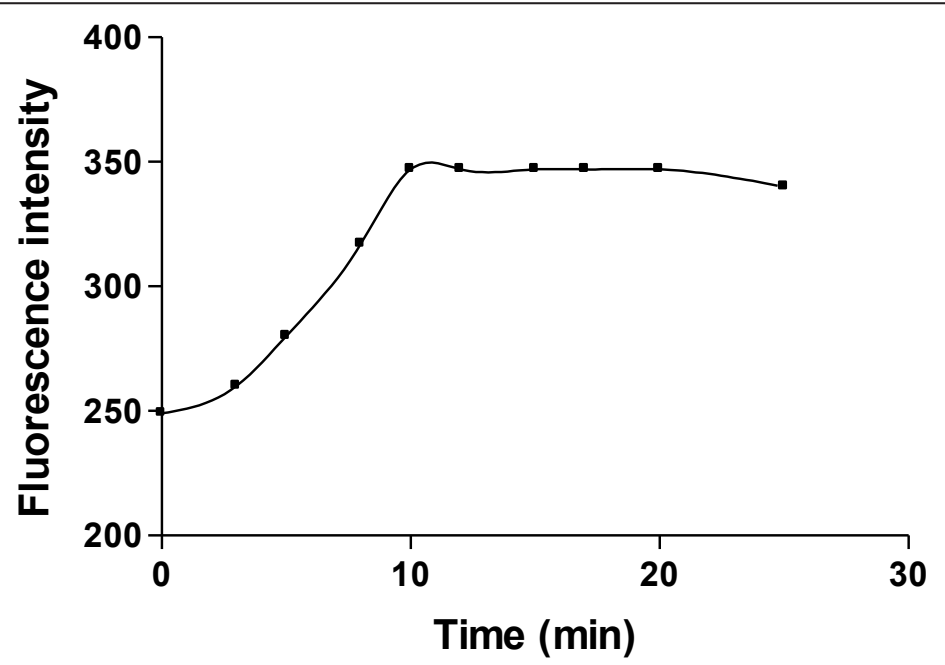

Figure 4 Effect of reaction time of on the fluorescence intensity of the reaction product of SER $\left(1 \mu \mathrm{gL}^{-1}\right)$ with FMOC-Cl. 
Table 1 Performance data of the proposed method

\begin{tabular}{cc}
\hline Parameter & Value \\
\hline -concentration range $\left(\mu \mathrm{gL} \mathrm{m}^{-1}\right)$. & $0.05-1.0$ \\
-Minimum detection limit, LOD $\left(\mu \mathrm{g} \mathrm{mL}^{-1}\right)$. & $5.34 \times 10^{-3}$ \\
-Limit of Quantification, LOQ $\left(\mu \mathrm{g} \mathrm{m}^{-1}\right)$. & 0.016 \\
-Correlation coefficient $(\mathrm{r})$. & 0.9999 \\
- Slope & 345.9 \\
-Intercept & -0.66 \\
$-S_{\mathrm{y} / x}$ & 0.89 \\
$-S_{a}$ & 0.56 \\
$-S_{b}$ & 0.99 \\
$-\%$ Error & 0.34 \\
\hline
\end{tabular}

$-\mathrm{S}_{\mathrm{y} / \mathrm{x}}=$ standard deviation of the residuals.

$-S_{a}=$ standard deviation of the intercept of regression line.

$-S_{b}=$ standard deviation of the slope of regression line

$-\%$ Error $=\mathrm{RSD} \% / \sqrt{ } \mathrm{n}$.

the analyte can be reliably detected, and the results are also abridged in Table 1.

LOQ and LOD were calculated according to the following equation: [23]

$$
\begin{aligned}
& \mathrm{LOQ}=10 \sigma / \mathrm{S} \\
& \mathrm{LOD}=3.3 \sigma / \mathrm{S}
\end{aligned}
$$

Where $\sigma$ : is the standard deviation of the intercept of regression line.

$S:$ is the slope of the calibration curve.

The proposed methods were evaluated for the accuracy as percent relative error (\% Error) and the precision as percent relative standard deviation (\% RSD) (Tables 1 and 2).

\section{Accuracy}

To test the validity of the proposed method, it was applied to the determination of an authentic sample of SER over the working concentration range. The results obtained were in good agreement with those obtained using a reference method. ${ }^{11)}$. Using Student's t-test and variance ratio F-test [24] revealed no significant

Table 2 Application of the proposed and reference methods to the determination of sertraline in pure form

\begin{tabular}{lll}
\hline Parameters & Spectrofluorimetric Method & $\begin{array}{l}\text { Reference } \\
\text { Method (11) }\end{array}$ \\
\hline 1-No.of Experiments. & 7 & 3 \\
2-Mean found (\%) & 100.31 & 99.92 \\
\pm SD. & 0.90 & 1.58 \\
\% R.SD. & 0.90 & 1.58 \\
3-Variance. & 0.81 & 2.496 \\
4-Student's t-value. & $0.51(2.31)$ & \\
5-Variance ratio F-test. & $3.08(5.14)$ & \\
\hline
\end{tabular}

Figures between parentheses are the tabulated $\mathrm{t}$ and $\mathrm{F}$ values respectively, at $p=0.05$ [24]. difference between the performance of the two methods regarding the accuracy and precision, respectively (Table 2).

The validity of the methods was proved by statistical evaluation of the regression lines, using the standard deviation of the residuals $\left(\mathrm{S}_{\mathrm{y} / \mathrm{x}}\right)$, the standard deviation of the intercept $\left(\mathrm{S}_{\mathrm{a}}\right)$ and standard deviation of the slope $\left(S_{\mathrm{b}}\right)$. The results are abridged in Table 1 . The small values of the figures point out to the low scattering of the points around the calibration line and high precision.

\section{Precision}

\section{i. Repeatability}

The repeatability was performed by applying the proposed methods for the determination of three concentrations of SER either in pure form or in tablets on three successive times, and the results are listed in Table 3.

\section{ii. Intermediate precision}

It was performed through repeated analysis of SER either in pure form or in tablets, using the concentrations showed in Table 3 for a period of 3 successive days. The results are summarized in Table 3.

\section{Pharmaceutical Applications}

The proposed methods were then applied to the determination of SER in its tablets. The methods were tested

Table 3 Validation of the proposed method for the

\begin{tabular}{|c|c|c|c|}
\hline $\begin{array}{c}\text { Concentration added } \\
\left(\mu \mathrm{g} \mathrm{mL^{-1 } )}\right.\end{array}$ & \% Recovery & $\% R S D$ & $\%$ Error \\
\hline \multicolumn{4}{|l|}{ SER } \\
\hline \multicolumn{4}{|l|}{ Intra-day } \\
\hline 0.2 & $98.75 \pm 0.65$ & 0.65 & 0.33 \\
\hline 0.4 & $100.41 \pm 1.07$ & 1.07 & 0.54 \\
\hline 0.6 & $98.66 \pm 0.5$ & 0.5 & 0.25 \\
\hline \multicolumn{4}{|l|}{ Inter-day } \\
\hline 0.2 & $99.98 \pm 0.82$ & 0.82 & 0.41 \\
\hline 0.4 & $100.63 \pm 0.85$ & 0.85 & 0.43 \\
\hline 0.6 & $100.74 \pm 1.17$ & 1.17 & 0.59 \\
\hline \multicolumn{4}{|l|}{$\begin{array}{c}\text { Lustral Tablets } \\
\text { (50 mg SER/tablet) }\end{array}$} \\
\hline \multicolumn{4}{|l|}{ Intra-day } \\
\hline 0.2 & $98.00 \pm 1.29$ & 1.29 & 0.65 \\
\hline 0.4 & $100.41 \pm 0.92$ & 0.92 & 0.46 \\
\hline 0.6 & $100.47 \pm 1.35$ & 1.35 & 0.68 \\
\hline \multicolumn{4}{|l|}{ Inter-day } \\
\hline 0.20 & $100.19 \pm 1.07$ & 1.07 & 0.54 \\
\hline 0.40 & $99.67 \pm 1.56$ & 1.56 & 0.78 \\
\hline 0.60 & $100.80 \pm 0.80$ & 0.80 & 0.40 \\
\hline
\end{tabular}
determination of sertraline in pure form and tablets

Each result is the average of four separate determinations. 
for linearity, specificity, accuracy, repeatability and precision according to ICH Q2B recommendations.

\section{Selectivity}

The selectivity of the method was investigated by observing any interference encountered from the common tablet excepients, such as talc, lactose, starch, avisil, gelatine, and magnesium stearate. These excepients did not interfere with the proposed method

\section{Accuracy}

The results of the proposed methods were statistically compared with those obtained using the reference method [11]. Statistical analysis [24] of the results, using Student's t-test and variance ratio F-test revealed no significant difference between the performance of the proposed and reference methods regarding the accuracy and precision, respectively (Table 4).

The reference is based on an HPLC determination of sertraline $\mathrm{HCl}$ either inpure form or in its tablets using a mobile phase consists of methanol: phosphate buffer (20: $80 \mathrm{v} / \mathrm{v})$ of $\mathrm{pH} 4.5$ with UV detection at $270 \mathrm{~nm}$.

\section{Analysis of biological fluid}

This investigation conforms to the Egyptian Community guidelines for the use of human in experiments. The human Ethics Committee of Faculty of Pharmacy, Mansoura University, approved the study.

The high sensitivity of the proposed method allowed the determination of SER in spiked and real human plasma. Following oral administration of a single $50 \mathrm{mg}$ sertraline dose after an over night fast, the mean plasma level of $0.05-0.2 \mu \mathrm{g} / \mathrm{mL}$ was achieved after 6.9 hour (25). This values lie within the working concentration range. Sertraline is extensively metabolized via N-desmethylation, oxidative deamination and subsequent reduction,

Table 4 Application of the proposed methods to the determination of sertraline in tablets

\begin{tabular}{lcc}
\hline & \multicolumn{2}{c}{ \% Recovery } \\
\cline { 2 - 3 } Preparations & 98.25 & 100.23 \\
\hline Lustral tablets & 101.00 & 98.51 \\
(50 mg sertraline /tablet) & 99.38 & 100.43 \\
& 99.80 & \\
& 99.30 & \\
& \\
& \\
-Mean found (\%) \pm SD. & $99.69 \pm 1.05$ \\
$\mathrm{t}$ - value & \\
F- value & \\
\hline The tabulated values of $\mathrm{t}$ and $\mathrm{F}$ are (2.45) and (6.94) respectively, at $\mathrm{p}=0.05$ \\
(24).
\end{tabular}

hydroxylation and glucuronide conjugation. About 40$45 \%$ of an administered dose is excreted in urine as unchanged drug [25].

The results are shown in Table 5 .

The extraction procedure described by Kim et al [26] was adopted here. The results are satisfactorily accurate and precise.

\section{Precision}

The within-day precision was evaluated through replicate analysis of blank human plasma samples spiked with different concentrations of the drug. The percentage recoveries based on the average of three separate determinations were $94.40 \pm 1.14$, thus indicating the high precision of the method (Table 5).

The inter-day precision was also evaluated through replicate analysis of plasma samples spiked with $0.1 \mu \mathrm{g}$ $\mathrm{mL}^{-1}$ of drug on four successive days. The percentage recoveries based on the average of four separate

Table 5 Application of the proposed methods to the determination of sertraline in spiked and real human plasma samples

\begin{tabular}{|c|c|c|c|}
\hline Sample & $\begin{array}{c}\text { Amount } \\
\text { added } \\
\left(\mu \mathrm{g} \mathrm{mL}^{-1}\right)\end{array}$ & $\begin{array}{c}\text { Amount } \\
\text { found } \\
\left(\mu \mathrm{gL} \mathrm{m}^{-1}\right)\end{array}$ & $\begin{array}{c}\% \\
\text { Recovery }\end{array}$ \\
\hline 1 -a-Plasma & 0.05 & 0.048 & 96.0 \\
\hline \multirow[t]{2}{*}{ (intra-day precision) } & 0.10 & 0.0939 & 93.90 \\
\hline & 0.20 & 0.1884 & 94.20 \\
\hline Mean & & & 94.40 \\
\hline$\pm \mathrm{SD}$ & & & 1.14 \\
\hline$\%$ RSD & & & 1.14 \\
\hline$\%$ Error & & & 0.66 \\
\hline 1-b-Plasma & 0.10 & 0.0930 & 93.00 \\
\hline \multirow[t]{3}{*}{ (inter-day precision) } & 0.10 & 0.0957 & 95.70 \\
\hline & 0.10 & 0.0923 & 92.30 \\
\hline & 0.10 & 0.0902 & 90.20 \\
\hline Mean & & & 92.80 \\
\hline$\pm \mathrm{SD}$ & & & 2.27 \\
\hline$\%$ RSD & & & 2.27 \\
\hline \% Error & & & 0.57 \\
\hline \multirow{3}{*}{$\begin{array}{l}\text { 2- Real Human } \\
\text { plasma }\end{array}$} & 0.10 & 0.0955 & 95.5 \\
\hline & 0.10 & 0.0912 & 91.20 \\
\hline & 0.10 & 0.090 & 90.00 \\
\hline Mean & & & 92.23 \\
\hline$\pm \mathrm{SD}$ & & & 2.89 \\
\hline$\%$ RSD & & & 2.89 \\
\hline$\%$ Error Mean & & & 1.67 \\
\hline
\end{tabular}

Each result is the average of three separate determinations. 
determinations were $92.80 \pm 2.27$. The results are shown in Table 5. On the other hand, for real human plasma, the percentage recoveries based on the average of three separate determinations were $92.23 \pm 2.89$.

\section{Molar ratio and mechanism of the reaction}

The stoichiometry of the reaction was studied adopting the limiting logarithmic method [27]. The fluorescence intensity of the reaction product was alternatively measured in the presence of excess of either FMOC-Cl or SER A plot of log fluorescence versus log [FMOC-Cl] and $\log [\mathrm{SER}]$ gave two straight lines, the values of the slopes are 0.707 and 0.985 respectively(Figure 5). Hence, it is concluded that, the molar reactivity of the reaction is $0.985 / 0.707$, i.e. the reaction proceeds in the ratio of 1: 1. Based on the observed molar reactivity of the reaction, and depending on the presence of secondary amino group and by analogy to similar reports $(18,20)$ dealing with the reaction of $\mathrm{FMOC}-\mathrm{Cl}$ with compounds containing secondary amino group, the reaction pathway proposed in scheme 1 is presented.
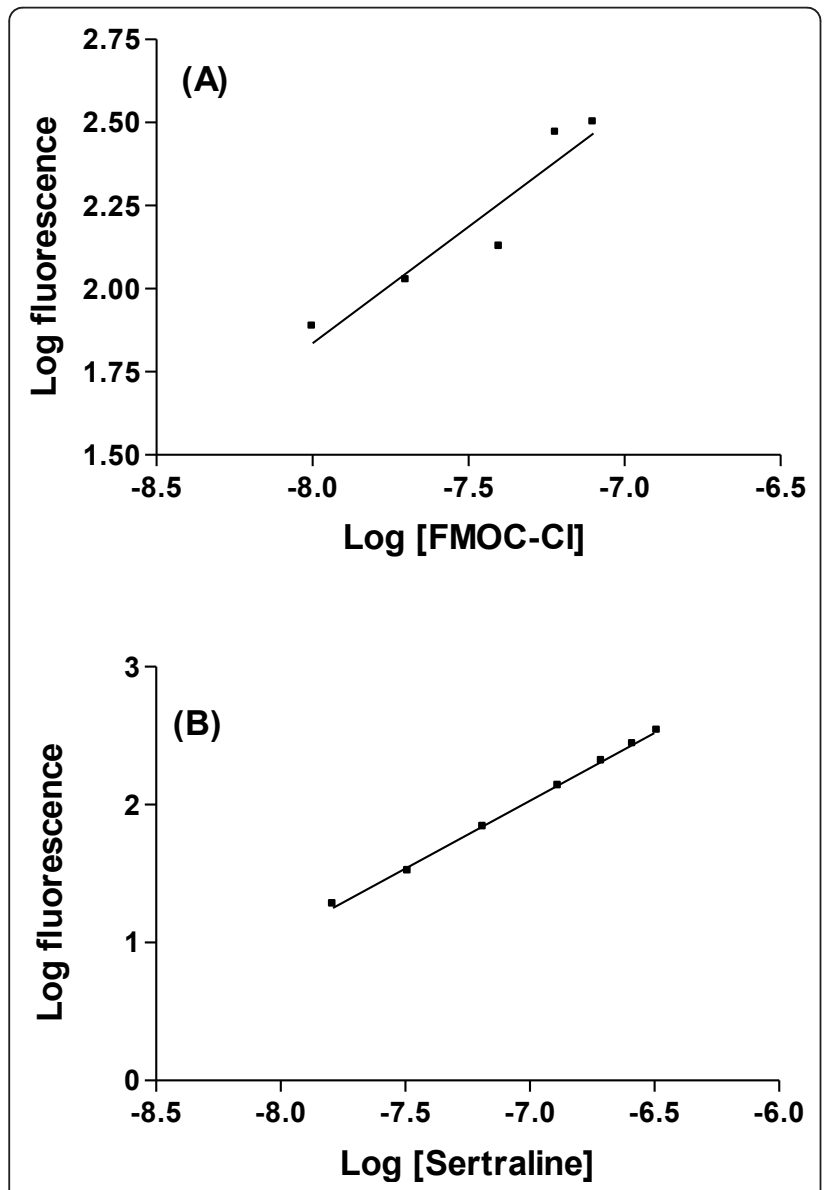

Figure 5 Limiting logarithmic plots for the molar ratio. (A) Log A vs. Log [FMOC-Cl] (B) Log A vs. log [Sertraline].

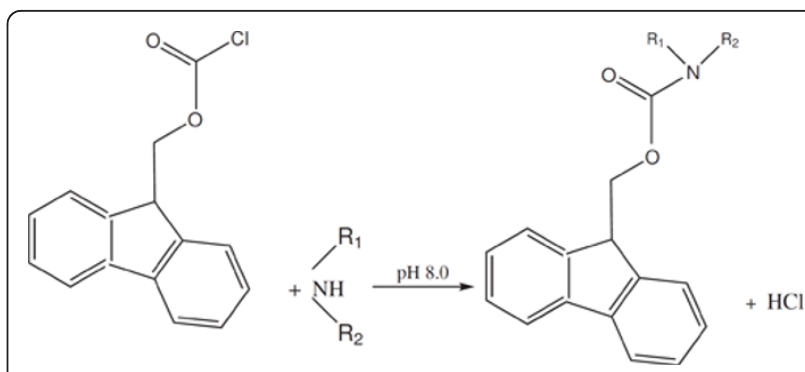

Scheme 1 Proposed reaction pathway between $\mathrm{FMOC}-\mathrm{Cl}$ and sertraline.

\section{Conclusion}

The proposed method has the advantage of being simple, sensitive and suitable for routine analysis in quality control laboratories. Also, it is suitable for the determination of sertraline in human plasma with minimum detection limit lower than the reported value. In addition, it could be applied to the determination of sertraline in its pharmaceutical preparation. The proposed method is considered to be specific for determination of SER in presence of its metabolite (deaminated form)

\section{Authors' contributions}

NME designed the proposed method, analysed the data stastistically and wrote the manuscript and collect the literature review. FB proposed, planned and supervised the whole work. AA carried out the experimental work. All the authors read and approved the final manuscript.

\section{Competing interests}

The authors declare that they have no competing interests.

Received: 26 June 2011 Accepted: 6 October 2011

Published: 6 October 2011

\section{References}

1. Kleemann A, Engel J, Kutscher B, Reichert D: Encyclopedia of Pharmaceutical Substances. Stuttgart, Germany: Thieme 2000

2. Onal A, Kepekci SE, Cetin SM, Ertürk S: Spectrophotometric determination of certain antidepressants in pharmaceutical preparations. J AOAC Int 2006, 89:966-971.

3. Darwish IA: Development and validation of spectrophotometric methods for determination of fluoxetine, sertraline, and paroxetine in pharmaceutical dosage forms. J AOAC Int 2005, 88:38-45.

4. Walash MI, Belal F, El-Enany N, El-Mansi H: Spectrophotometric Determination of the Antidepressants Sertraline and Paroxetine $\mathrm{HCl}$ using 2,4-Dinitrofluorobenzene. Int J Biomed Sci 2010, 6:252-259.

5. Vela MH, Quinaz Garcia MB, Montenegro MC: Electrochemical behaviour of sertraline at a hanging mercury drop electrode and its determination in pharmaceutical products. Fresenius J Anal Chem 2001, 369:563-566.

6. Conley JM, Symes SJ, Kindelberger SA, Richards SM: Rapid liquid chromatography-tandem mass spectrometry method for the determination of a broad mixture of pharmaceuticals in surface water. $J$ Chromatogr A 2008, 1185:206-215.

7. Esrafili A, Yamini Y, Shariati S: Hollow fiber-based liquid phase microextraction combined with high-performance liquid chromatography for extraction and determination of some antidepressant drugs in biological fluids. Anal Chim Acta 2007, 604:127-133.

8. Castaing N, Titier K, Receveur-Daurel M, Le-Déodic M, Le-bars D, Moore N, Molimard M: Quantification of eight new antidepressants and five of their active metabolites in whole blood by high-performance liquid 
chromatography-tandem mass spectrometry. J Anal Toxicol 2007, 31:334-341.

9. Malfará WR, Bertucci C, Costa Queiroz ME, Dreossi Carvalho SA, Pires Bianchi Mde L, Cesarino EJ, Crippa JA, Costa Queiroz RH: Reliable HPLC method for therapeutic drug monitoring of frequently prescribed tricyclic and nontricyclic antidepressants. J Pharm Biomed Anal 2007, 44:955-962.

10. Walash MI, El-Brashy A, El-Enany N, Kamel M: High Performance Liquid Chromatographic Determination of Sertraline in Presence of Its Degradation Product. Anal Lett 2010, 43:1434-1447.

11. Erk N: Rapid and simple methods for quantitative analysis of some antidepressant in pharmaceutical formulations by using first derivative spectrophotometry and HPLC. Farmaco 2003, 58:1209-1216.

12. Wille SM, Van Hee P, Neels HM, Van Peteghem CH, Lambert WE: Comparison of electron and chemical ionization modes by validation of a quantitative gas chromatographic-mass spectrometric assay of new generation antidepressants and their active metabolites in plasma. $J$ Chromatogr A 2007, 1176:236-245.

13. Berzas Nevado JJ, Villaseñor Llerena MJ, Guiberteau Cabanillas C, Rodríquez Robledo V, Buitrago S: Sensitive capillary GC-MS-SIM determination of selective serotonin reuptake inhibitors: reliability evaluation by validation and robustness study. J Sep Sci 2006, 29:103-113.

14. Bosch ME, Sánchez AJ, Rojas FS, Ojeda CB: Analytical methodologies for the determination of sertraline. J Pharm Biomed Anal 2008, 48:1290-1302.

15. Lajeunesse A, Gagnon C, Sauvé S: Determination of basic antidepressants and their $\mathrm{N}$-desmethyl metabolites in raw sewage and wastewater using solid-phase extraction and liquid chromatography- tandem mass spectrometry. Anal Chem 2008, 80:5325-5333.

16. Körös A, Varga Z, Molnár-Perl I: Simultaneous analysis of amino acids and amines as their o-phthalaldehyde-ethanethiol-9-fluorenylmethyl chloroformate derivatives in cheese by high-performance liquid chromatography. J Chromatogr A 2008, 1203:146-152.

17. Khedr A, Sheha MM, Darwish IA: Sensitive determination of trimetazidine in spiked human plasma by HPLC with fluorescence detection after precolumn derivatization with 9-fluorenylmethyl chloroformate. J Chromatogr B 2007, 856:337-342.

18. Główka FK, Karaźniewicz-Łada M: Determination of roxithromycin in human plasma by HPLC with fluorescence and UV absorbance detection: application to a pharmacokinetic study. J Chromatogr B 2007, 852:669-673.

19. Bahrami G, Mohammadi B: Determination of clarithromycin in human serum by high-performance liquid chromatography after pre-column derivatization with 9-fluorenylmethyl chloroformate: application to a bioequivalence study. J Chromatogr B 2007, 850:417-422.

20. Yun MH, Kwon Kl: High-performance liquid chromatography method for determining alendronate sodium in human plasma by detecting fluorescence: application to a pharmacokinetic study in humans. J Pharm Biomed Anal 2006, 40:168-172.

21. Bahrami G, Mirzaeei Sh, Kiani A: Sensitive analytical method for Topiramate in human serum by HPLC with pre- column fluorescent derivatization and its application in human pharmacokinetic studies. $J$ Chromatogr B 2004, 813:175-180.

22. Sun Y, Nakashima MN, Takahashi M, Kuroda N, Nakashima K: Determination of bisphenol A in rat brain by microdialysis and column switching highperformance liquid chromatography with fluorescence detection. Biomed Chromatogr 2002, 16:319-326.

23. Guidance for Industry; Q2B of Analytical Procedures: Methodology. International Conference on Hormonization (ICH) 1996 [http://www.fda.gov/ downloads/Regulator\%20yInformation/Guidances/UCM128049.pdf].

24. Miller JN, Miller JC: Statistics and Chemometrics for Analytical Chemistry. England, UK: Prentice Halli, 5 2005, 256.

25. Moffat AC, Osselton MD, Widdop B: Clark's Analysis of Drugs and Poisons in pharmaceuticals, body fluids and postmortem material. London, UK: The Pharmaceutical Press; 3 2004, 1594-1595.

26. Kim KM, Hung BH, Choi MH, Woo JS, Paeng KJ, Chung BC: Rapid and sensitive determination of sertraline in human plasma using gas chromatography-mass spectrometry. J Chromatogr B 2002, 769:333-339.

27. Rose J: Advanced Physico-Chemical Experiments. London: Pitman; 1964.
doi:10.1186/1752-153X-5-56

Cite this article as: El-Enany et al: Spectrofluorimetric determination of sertraline in dosage forms and human plasma through derivatization with 9-fluorenylmethyl chloroformate. Chemistry Central Journal 2011 5:56.

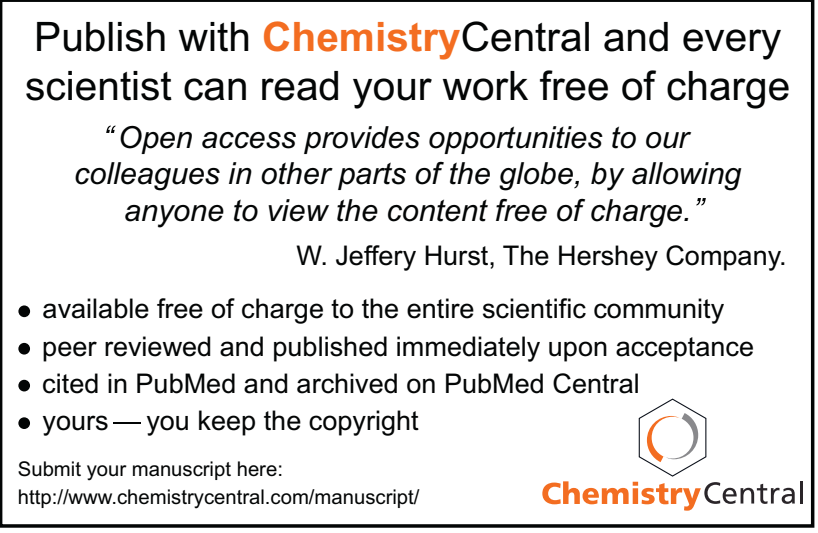

